\title{
Sexual Maturation May Affect the Levels of n-6 PUFA in Muscle Tissues of Male Mice
}

\author{
Chang Seok Park ${ }^{1}$, Inho Choi ${ }^{2}$ and Young Sik Park ${ }^{3 *}$ \\ ${ }^{1}$ National Institute of Animal Science, R.D.A., Suwon 441-350, Korea, ${ }^{2}$ School of Biotechnology, Yeungnam University, \\ Gyeongsan 712-749, Korea, ${ }^{3}$ School of Animal Science and Biotechnology, Kyungpook National University, \\ Sangju 742-711, Korea
}

\begin{abstract}
Lipid metabolism in mature male mice may be different from immature male mice, but the relationship of lipid metabolism, especially n-6 fatty acid metabolism, and sexual maturation is not clearly established. This study was carried out to elucidate whether sexual maturation may affect the metabolism of functional $n-6$ fatty acids of lipid components by investigating the composition of fatty acids in the longissimus muscle tissues of mature and immature male mice with GC and analyzing the expression of genes and proteins for synthesis of n-6 fatty acids with real-time PCR and western blotting, respectively. Mature male mice showed significantly higher testosterone level in the sera. Similarly, n-6 fatty acids, levels of linoleic acid (LA 18:2n-6) and total n-6 PUFA (Polyunsaturated fatty acids) were increased, but the levels of $\gamma$-linolenic acid (GLA; 18:3n-6), dihomo- $\gamma$ -linolenic acid (DGLA; 20:3n-6) and arachidonic acid (AA; 20:4 n-6) were decreased in the mature male mice. mRNA levels of $\Delta$ 5-desaturase (FASD1) and elongase (ELOVL5) genes related to n-6 fatty acid metabolism increased. However, the level of FADS1 protein only increased in mature male mice. In conclusion, this study suggested that sexual maturation of male mice affected $n-6$ fatty acid metabolism by stimulating the expression of enzyme FADS1 of n-6 PUFA metabolism.
\end{abstract}

(Key words : ELOVL5, FADS2, FADS1, Gender, n-6 fatty acids)

\section{INTRODUCTION}

Mature livestock has supplied animal food, of which quality is an important factor for maintenance of the body condition in healthy and wellbeing state (Weaver et al., 2009; Barton et al., 2011). The animal food quality is partly depended on levels of the functional fatty acid, as $\mathrm{\gamma}$ linolenic acid (Bu et al., 2007; Senapati et al., 2008).

Drastic increase of body weight occurs during male sexual maturation, when lipid tissue is known to be accumulated (Salma et al., 2007). The higher lipid in body tissues may be related to the initiation of sexual puberty (Childs et al., 2012). Also, the expression of puberty in male is closely related to increase of blood testosterone level (Childs et al., 2008). The higher testosterone is known to initiate the sexual maturation in male.

Therefore, sexual maturation in male is induced by higher testosterone and affected by higher lipid content (Ogura et al., 2010). This deduction suggests that the increase of testosterone may affect the increase of lipid metabolism(de Alaniz and Marra, 2003).

This study is carried out to elucidate the relationship between sexual maturation and n-6 fatty acid metabolism by investigating the composition of fatty acids and examining the expression of genes and proteins for $n-6$ fatty acid metabolism in longissimus muscle tissue of male mice.

\section{MATERIALS AND METHODS}

\section{Animals}

Institute for Cancer Research (ICR) mice of 3, 5 and 7-wk-old were randomly divided into groups of 5 mice each. The mice were allowed to acclimate at least for $7 \mathrm{~d}$ with chow (AIN 93 G; Feedlab Co., Gyeonggi-Do, Korea) and water ad libitum. All mice were reared in the facility that was maintained at a temperature of $23 \pm 2{ }^{\circ} \mathrm{C}$, relative humidity of $50 \pm 5 \%$ and light/dark cycle of $12 \mathrm{~h}$. All

* Corresponding author: Young Sik Park, School of Animal Science and Biotechnology, Kyungpook National University, Sangju 742711, Korea. Tel: 054-530-1223, Fax: 054-530-1649, E-mail: yspark@knu.ac.kr 
experiments were conducted in accordance with the policies and recommendations of Animal Care and Use Committee of the Kyungpook National University.

\section{Reagents}

Solvents were purchased from several chemical companies. Supelco $^{\text {TM }} 37$ and BHT (2,6 Di-tert-butyl-4-methyl phenol) were purchased from Sigma Chemical Co. Takara's Premix Ex Taq from Takara Bio Inc (Shiga, Japan), $2 \times$ SYBR Ex Taq from Takara Bio Inc (Shiga, Japan), RIPA buffer from Cell Signaling Technology Inc(MA, USA), antibodies (FADS2, ELOVL5 and FADS1) and secondary antibodies conjugated to goat or rabbit radish peroxidase from Santa Cruz (CA, USA), and chemiluminescence from Amersham ECL Plus (IL, USA).

\section{Preparation of samples}

Muscle sample was collected from male mice of 3, 5 and 7 weeks old. The mice were anesthetized by injecting intra-peritoneally $2.5 \%$ tribromoethanol (Sigma-Aldrich, St. Louis, MO, USA) of $0.015-0.017 \mathrm{ml}$ per gram of body weight. Muscle tissues were recovered from M. longissimus of mice and completely minced with scissors, then stored at $-80^{\circ} \mathrm{C}$ until further analysis.

Blood was collected in an EDTA coated tube (BD Vacutainer, Franklin Lakes NJ USA) by punching retroorbital venous plexus after light etherization. It was centrifuged at 3,000 rpm for $15 \mathrm{~min}$ at room temperature the upper layer of serum was immediately isolated and stored at $-80^{\circ} \mathrm{C}$.

\section{Analysis of steroid hormones by electro-che- miluminescence immunoassay}

Serum collected from $1 \mathrm{ml}$ of blood samples at $9 \mathrm{AM}$ was used for analysis of testosterone (T) and 17ß-estradiol $\left(\mathrm{E}_{2}\right)$.

Steroid hormones were analyzed with an electrochemiluminescence immunoassay (ECLIA; Roche, Mannheim, Germany) based on competition principle for either testosterone or $17 \beta$-estradiol. Results were determined by the calibration curve which was instrument-specifically generated by 2-point calibration and a master curve provided by the reagent barcode (Roche, Mannheim, Germany).

\section{Analysis of $n-6$ fatty acids by gas chromatography}

Five $\mathrm{ml}$ of chloroform/methanol (2:1)solution and $10 \mu \mathrm{l}$ of 7.2\% BHT (2, 6 Di-tert-butyl-4-methyl phenol) solution were added to the minced $M$. longissimus tissue. The tissue was homogenized at 2,500 rpm for $10 \mathrm{~min}$ by a Polytron Homogenizer PT 1200 CL (Kinemarica AG, Littau, Switzerland). After incubating for $6 \mathrm{~h}$ to extract crude lipid, the sample was mixed with $25 \% \mathrm{NaCl}$ solution. The lower lipid layer was collected and dried by ventilation with $\mathrm{N}_{2}$ gas. Then, $2 \mathrm{ml}$ of $6 \%$ methanol/sulfuric acid (94:6) solution were added to the dried sample for the methylation of fatty acids. The methylated samples were transferred to a vial and stored at $4^{\circ} \mathrm{C}$ until analyzed by gas chromatography (GC).

The methylated samples, fatty acid methyl esters (FAME), were analyzed onto the Agilent 7890A gas chromatographic system with the MPS2 auto sampler and their concentrations were calculated on the Agilent programs. In brief, one micro liter of sample was injected onto the SPTM-2560 column $(100 \mathrm{~m} \times 0.25 \mathrm{~mm}$ I.D, $0.2 \mu \mathrm{m})$. Helium gas (ultra-pure) was used as the carrier gas at a constant flow rate of 1.5 $\mathrm{ml} / \mathrm{min}$. The oven temperature was maintained at $121^{\circ} \mathrm{C}$ for $1 \mathrm{~min}$, and then increased to $140^{\circ} \mathrm{C}$ by $20^{\circ} \mathrm{C} / \mathrm{min}$. It was then slowly increased to $190^{\circ} \mathrm{C}$ at a rate of $4{ }^{\circ} \mathrm{C} / \mathrm{min}$ and finally by $3{ }^{\circ} \mathrm{C} / \mathrm{min}$ up to $260^{\circ} \mathrm{C}$ where it was maintained for $5 \mathrm{~min}$. Separation of fatty acids was achieved by GC installed with a flame-ionization detector. The FAME samples were quantified against an external standard, Supelco $^{\mathrm{TM}}$ 37. Each fatty acid recovered was calculated as a percentage of the cumulative of all fatty acids in the muscle.

\section{Analysis of gene expression for FADS2, ELOVL5, and FADS1 by real-time PCR}

The RNA was isolated from mouse muscle tissues in RNase-free environment using Trizol reagents (Invitrogen, CA, USA) according to the manufacturer's instruction. The RNA was quantified by UV absorbance (Nano Drop 2000, Thermo Scientific, NC, USA) and its amount was calculated by the A260 and A280/A260 ratios.

The isolated RNA was subjected to cDNA synthesis. One $\mu \mathrm{g}$ of RNA was added as a template in $10 \mu \mathrm{l}$ of reaction solution containing $1 \mu \mathrm{l}$ of dNTP Mix (final concentration 0.5 $\mathrm{mM}), 1 \mu \mathrm{l}$ of oligo (dT) primer, and nuclease free water. Generally, the volume of template RNA was as much as 8 11. The reaction was allowed to occur at $70^{\circ} \mathrm{C}$ for $5 \mathrm{~min}$ 
and then stopped in ice for $5 \mathrm{~min}$. For the reverse transcription reaction, subsequently, $10 \mu \mathrm{l}$ of aliquots $(3 \mu \mathrm{l}$ of $5 \times$ Improve-II $^{\mathrm{TM}}$ reaction buffer, $3 \mu \mathrm{l}$ of $25 \mathrm{mM} \mathrm{MgCl}_{2}, 1 \mu \mathrm{l}$ of Im-Prom Reverse Transcriptase, $0.5 \mu \mathrm{l}$ of recombinant RNasin $^{\circledR}$ Ribonuclease inhibitor and $2.5 \mu$ of nuclease free water) were added to each reaction tube in ice. Finally, total $20 \mu \mathrm{l}$ of reaction solution was incubated at $42^{\circ} \mathrm{C}$ for $60 \mathrm{~min}$. Then, it was heated at $70^{\circ} \mathrm{C}$ for $15 \mathrm{~min}$ to stop the reverse transcription and stored at $-20^{\circ} \mathrm{C}$ until use for real-time PCR.

Primers were designed using Primer Express 2.0 (Applied Biosystems, CA, USA) and checked with BLAST searches against GenBank. Primers for FADS2, ELOVL5 and FADS1 genes targeted in this study are shown in Table 1.

For real-time PCR, $1 \mu \mathrm{g}$ of cDNA was diluted to $0.1 \mu \mathrm{g}$ with water and the diluted cDNA was used as a template in the amplification reaction that was performed in $20 \mu \mathrm{l}$ of the solution mixed with $1 \mu \mathrm{l}$ of diluted cDNA, $10 \mu \mathrm{l}$ of $2 \times$ SYBR Ex Taq (Takara Bio Inc., Shiga, Japan), $0.4 \mu$ of Rox Dye I (Takara Bio Inc., Shiga, Japan), $2 \mu$ of each primer and $4.6 \mu \mathrm{l}$ of water. The reaction was amplified by a Stepone Real-Time PCR Detection System (Applied Biosystems, CA. USA). Thermal cycling parameters were as follows: an initial denaturation $\operatorname{step}\left(95^{\circ} \mathrm{C}\right.$ for $\left.30 \mathrm{~s}\right)$, followed by 40 cycles of denaturation $\left(95^{\circ} \mathrm{C}\right.$ for $\left.5 \mathrm{~s}\right)$ and annealing/extension $\left(60^{\circ} \mathrm{C}\right.$ for $\left.30 \mathrm{~s}\right)$ in a 96 -well optical plate.

The expression of mRNA was standardized by $\beta$-actin and the expression level was calculated as the difference between the threshold values of the two genes $\left(2^{-\Delta \mathrm{Ct}}\right)$. Data were analyzed with the comparative cycle threshold $(\mathrm{Ct})$ method: the expression of target genes in muscle tissues of the 7 -wk-old mice was normalized with the expression of $\beta$-actin gene and compared to the expression of corresponding genes in muscle of the 3-wk-old mice to generate $\Delta \mathrm{Ct}$ values. The relative quantities (RQ) were calculated with the equation: $\mathrm{RQ}=2^{-\Delta \Delta \mathrm{Ct}}$. Melting curve analysis was always performed during real-time PCR to analyze and verify the specificity of the reaction.

\section{Analysis of proteins for $n-6$ PUFA metabolism by Western blotting}

Muscle tissues were homogenized in RIPA buffer $(20 \mathrm{mM}$ Tris- $\mathrm{HCl}, 150 \mathrm{mM} \mathrm{NaCl}, 1 \mathrm{mM} \mathrm{Na} 2$ EDTA, $1 \mathrm{mM}$ EGTA, $1 \% \quad$ NP-40, $1 \%$ sodium deoxycholate, $2.5 \mathrm{mM}$ sodium pyrophosphate, $1 \mathrm{mM}$ $\beta$-glycerophosphate, $1 \mathrm{mM} \mathrm{Na}_{3} \mathrm{VO}_{4}, 1$ $\mathrm{g} / \mathrm{ml}$ leupeptin, $1 \mathrm{mM}$ PMSF Cell Signaling Technology Inc, MA, USA). The lysates were clarified by centrifugation at $13,000 \mathrm{rpm}$ for $40 \mathrm{~min}$. All procedures were carried out at $4^{\circ} \mathrm{C}$ and stored at $-80^{\circ} \mathrm{C}$. Protein concentrations of the muscle homogenates were determined using a Bradford assay. SDS-PAGE was performed using $12 \%$ agarose gels. Proteins were transferred onto nitrocellulose membranes, blocked for 2 $\mathrm{h}$ with skim milk, and exposed to the respective primary antibody for overnight at $4^{\circ} \mathrm{C}$. FADS2 (sc-109272), ELOVL5 (sc-135062) and FADS1 (sc-101953) proteins bound to their specific antibodies (Santa Cruz, CA, USA) were detected by incubating with secondary antibodies conjugated to goat (sc-2922)- or rabbit (sc-2004) radish peroxidase (Santa Cruz, $\mathrm{CA}$, USA) for $2 \mathrm{~h}$ at room temperature. Enhanced chemiluminescence (Amersham, Arlington Hts, IL, USA) with a Davinch-chemi ${ }^{\mathrm{TM}}$ Camera system was used to detect immune positive areas. The positive areas for FADS2, ELOVL5 and FADS1 proteins were normalized by the positive area for $a-$ tubulin.

\section{Statistical analysis}

All results were expressed as mean \pm standard deviation (SD). Comparisons between the treatments were performed by one way ANOVA, if necessary, followed by multiple range tests. Especially, SPSS v19.0 (SPSS Inc., Chicago, IL, USA) was used for the comparison of fatty acid levels among mice muscle tissues.

Table 1. Primers used in this study

\begin{tabular}{llc}
\hline \multirow{2}{*}{ Genes } & \multicolumn{2}{c}{ Primers } \\
\cline { 2 - 3 } & \multicolumn{1}{c}{ forward } & reverse \\
\hline \hline FADS2 (NM_019699.1) & CCTCAGCCAACTGGTGGAA & CTTTATGTCCGGGTCCTTGTG \\
ELOVL5 (NM_134255.3) & AGGAAGCAGCGAAAGGATTGA & CTATGAGCGTCAGGGCACAA \\
FADS1 (NM_146094.2) & CGACATGGAATCACCTGCTACA & GGTCCTTGCGGAAGCAGTTA \\
B-actin (NM_007393.3) & GATGGTGGGAATGGGTCAGA & TCCATGTCGTCCCAGTTGGT \\
\hline
\end{tabular}




\section{RESULTS}

\section{Effect of sexual maturity on level of testosterone and $17 \beta$-estradiol in male mice}

The sexual maturity is known to be closely related to reproductive steroid hormones in male mice. To confirm the relationship between sexual maturity and steroid hormone levels in male mice, blood levels of testosterone $(\mathrm{T})$ and $17 \beta$ estradiol $\left(\mathrm{E}_{2}\right)$ in mature and immature mice were investigated by ECLIA as shown in Fig. 1.

Testosterone level in male mice was significantly higher $(\mathrm{P}$ $<0.05)$ in 7 -wk-old group $(7.94 \pm 4.95 \mathrm{ng} / \mathrm{ml})$ than in 3-wkold group $(0.06 \pm 0.02 \mathrm{ng} / \mathrm{ml})$. However, $E_{2}$ level of 7-wk-old male mice $(13.16 \pm 2.59 \mathrm{pg} / \mathrm{ml})$ was not significantly $(\mathrm{P}>0.05)$ different from 3-wk-old male mice $(14.38 \pm 3.70 \mathrm{pg} / \mathrm{ml})$. The results suggested that sexual maturity in male mice is closely related to the increase of steroid hormone, $\mathrm{T}$.

\section{Effect of sexual maturity on levels of $n-6$ fatty acids in muscle tissues of male mice}

Generally, 3-, 5- and 7-week-old mice are classified as to be in the stages of pre-puberty, puberty and sexual maturity, respectively. In order to analyze sexual maturity effects in metabolism of n-6 PUFA, the n- 6 fatty acid composition in the M. longissimus collected from pre-pubertal-, pubertal-, or sexually matured- male mouse were analyzed by GC(Table 2).

The levels of total n-6 fatty acids in 3-, 5- and 7-wk-old
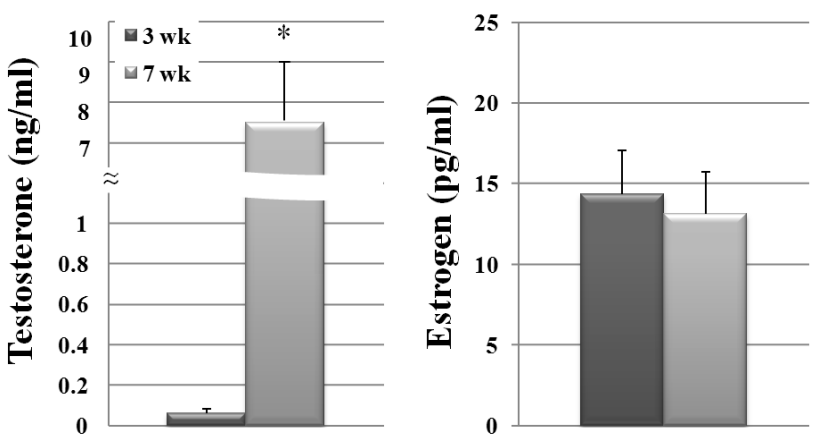

Fig. 1. Effect of age on $T$ and $E_{2}$ levels in male mice. The serum levels of the steroid hormones were measured by ECLIA in 3- and 7-wk-old male mice and were expressed as mean $\pm S D$ (Error bars). Asterisk (*) means significant difference between means at $\mathrm{P}<0.05$.
Table 2. Effect of age on levels of n-6 fatty acids in $M$. longissimus of male mice

\begin{tabular}{lrrr}
\hline n-6 Fatty & \multicolumn{3}{c}{ Ages } \\
\cline { 2 - 4 } acids & \multicolumn{1}{c}{$3 \mathrm{wk}$} & \multicolumn{1}{c}{$5 \mathrm{wk}$} & \multicolumn{1}{c}{$7 \mathrm{wk}$} \\
\hline \hline LA & $18.27 \pm 1.15^{\mathrm{b}}$ & $21.11 \pm 0.88^{\mathrm{a}}$ & $22.53 \pm 1.52^{\mathrm{a}}$ \\
GLA & $0.30 \pm 0.01^{\mathrm{a}}$ & $0.27 \pm 0.01^{\mathrm{b}}$ & $0.26 \pm 0.01^{\mathrm{b}}$ \\
DGLA & $0.80 \pm 0.12^{\mathrm{a}}$ & $0.56 \pm 0.05^{\mathrm{b}}$ & $0.39 \pm 0.07^{\mathrm{b}}$ \\
AA & $3.74 \pm 0.63^{\mathrm{a}}$ & $2.85 \pm 0.40^{\mathrm{b}}$ & $2.16 \pm 0.45^{\mathrm{b}}$ \\
Total & $23.62 \pm 1.34^{\mathrm{b}}$ & $25.30 \pm 0.84^{\mathrm{ab}}$ & $25.61 \pm 0.78^{\mathrm{a}}$ \\
\hline
\end{tabular}

Values are expressed as means $\pm \mathrm{SD}, \mathrm{n}=5$.

${ }^{a, b}$ Values with unlike different letters in each row are significantly different $(\mathrm{P}<0.05)$.

mice were $23.62 \pm 1.34 \%, 25.30 \pm 0.84 \%$, and $25.61 \pm 0.78 \%$, respectively. The result showed that the level of total n-6 fatty acids in muscle tissues significantly increased as male mice sexually mature $(\mathrm{P}<0.05)$.

However, levels of LA in 5-wk-old mice $(21.11 \pm 0.88 \%)$ and 7-wk-old mice $(22.53 \pm 1.52 \%)$, were significantly higher $(\mathrm{P}<0.05)$ than that in 3 -wk-old mice $(18.27 \pm 1.15 \%)$. LA level significantly increased as male mice sexually mature $(\mathrm{P}$ $<0.05$ ).

Level of GLA in 3-wk-old mice $(0.30 \pm 0.01 \%)$ was significantly higher $(\mathrm{P}<0.05)$ than those in 5-wk-old mice $(0.27 \pm 0.01 \%)$ and 7 -wk-old mice $(0.26 \pm 0.01 \%)$. GLA levels significantly reduced as male mice sexually mature $(\mathrm{P}<0.05)$.

Level of DGLA in 3-, 5-, and 7-wk-old mice were $0.80 \pm$ $0.12 \%, 0.56 \pm 0.05 \%$ and $0.39 \pm 0.07 \%$, respectively. DGLA level significantly decreased as male mice sexually mature ( $\mathrm{P}$ $<0.05$ ).

Level of AA in 3-wk-old mice $(3.74 \pm 0.63 \%)$ was significantly higher $(\mathrm{P}<0.05)$ than those in 5 -wk-old mice $(2.85 \pm 0.40 \%)$ and 7-wk-old mice $(2.16 \pm 0.45 \%)$. That is, AA level significantly decreased as male mice sexually mature $(\mathrm{P}<0.05)$.

Thus, these results suggested that sexual maturation affected the level of n-6 PUFA in muscle tissue of male mice. Especially, the levels of LA and total n-6 PUFA was increased, but the levels of GLA, DGLA and AA were decreased in mature male mice.

\section{Effect of sexual maturity on expression of genes for $n-6$ PUFA metabolism in male mice}

The previous results showed that sexual maturity affected levels of $n-6$ PUFA as well as testosterone in muscle tissue 
of male mice. The levels of n-6 PUFA was known to be controlled by 3 types of enzymes, $\Delta 6$-desaturase (FASD2), elongase (ELOVL5), and $\Delta 5$-desaturase (FASD1). Thus, previous result suggested an increase of LA and the decreases of GLA, DGLA and AA in mature mice may indicate the decreased gene expression of FASD2 enzyme and/or the increased gene expression of ELOVL5 and FASD1 enzymes. Thus, to elucidate how the sexual maturity affects expression of genes for these enzymes related to n-6 PUFA metabolism, mRNA levels of these enzymes in $M$. longissimus of male mice were checked by real-time PCR Fig. 2.

For FADS2, relative mRNA expression $(\mathrm{RmE})$ of 7-wk-old male mice was $1.18 \pm 0.12$, that was not different from $\mathrm{RmE}$ $(1.00 \pm 0.15)$ of 3 -wk-old male mice $(\mathrm{P}>0.05)$.

For ELOVL5, RmE of 7-wk-old male mice was $1.76 \pm$ 0.29 , significantly higher than that $(1.00 \pm 0.25)$ of 3 -wk-old male mice $(\mathrm{P}<0.05)$.

For FADS1, RmE of 7-wk-old male mice was $1.31 \pm 0.07$, significantly higher than that $(1.00 \pm 0.14)$ of 3 -wk-old male mice $(\mathrm{P}<0.05)$.

The above results suggest that sexual maturity in male increase the gene expression for ELOVL5 and FADS1 enzymes. It indicates that the increase of LA and the decreases of GLA, DGLA and AA in mature mice may not relate to the decreased activity of FASD2, but to the increased activity of ELOVL5 and FASD1 enzymes.

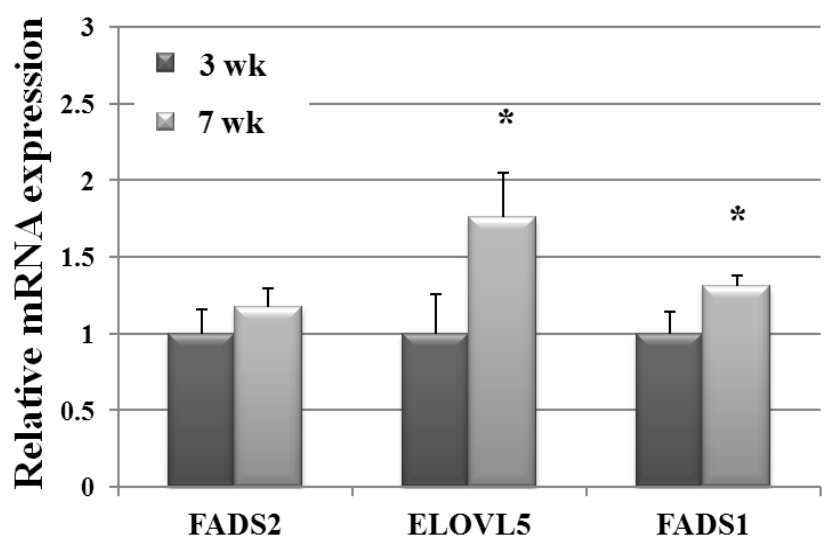

Fig. 2. Effect of age on mRNA levels of FADS2, ELOVL5, and FADS1 in male mice. Expression of genes, FADS2, ELOVL5 and FADS1, were measured by real-time PCR at 3- and 7-wk-old male mice and normalized with $\beta$-actin. The relative mRNA expression (RmE) levels of 7 wk-old male mice were expressed as compared to 3-wk-old male mice as mean $\pm \mathrm{SD}$ (Error bars). Asterisk $(*)$ means significant difference between means at $\mathrm{P}<0.05$.

4. Effect of sexual maturity on levels of proteins for $\mathrm{n}-6$ PUFA metabolism in the male mice

Our previous results showed that sexual maturity in male affects gene expression of ELOVL5 and FADS1 enzymes.
(A)

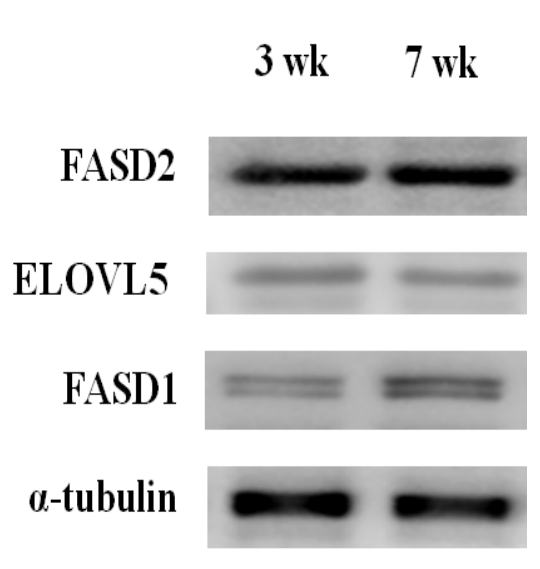

(B)

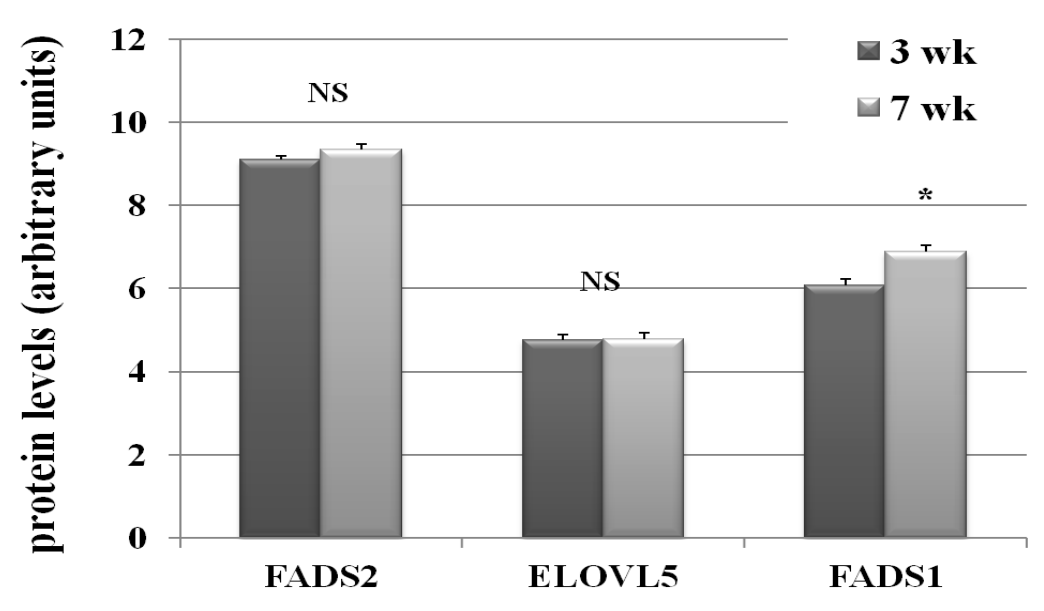

Fig. 3. Effect of age on the levels of FADS2, ELOVL5 and FADS1 enzymes in male mice. (A) Expression of FADS2, ELOVL5 and FADS1 protein at 3 and 7-wk-old mice by western blot. (B) Expression of enzymes was normalized with a-tubulin. Relative enzymes expression levels in muscle tissues were measured using Image $\mathrm{J}$ software. The levels of enzymes, FADS2 and ELOVL5, were not significantly different between 3 and 7-wk-old mice $(P>0.05)$, but FASD1 level of 7 -wk-old mice was significantly higher than 3 -wk-old mice $(P<0.05)$. Asterisk $\left(^{*}\right)$ means significant difference between means at $P<0.05$. 
Thus, these results suggest that mature male has higher levels of enzymes, especially ELOVL5 and FADS1 proteins in their muscle tissue. To clarify how the sexual maturity may affect levels of n-6 PUFA enzymes, the protein expression of these enzymes was checked by western blot in M. longissimus of male mice (Fig. 3).

For FADS2 protein, relative protein expression (RpE) level of 7-wk-old male mice was $9.35 \pm 0.12$, that was not different from $\operatorname{RpE}(9.11 \pm 0.08)$ of 3 -wk-old male mice $(\mathrm{P}>$ 0.05).

For ELOVL5 protein, the RpE level of 7-wk-old male mice was $4.79 \pm 0.13$, that was higher than that $(4.76 \pm 0.14)$ of 3-wk-old male mice $(\mathrm{P}>0.05)$. But, there was no significant difference between mature and immature mice in ELOVL5 protein of muscle tissue.

For FADS1 protein, RpE level of 7-wk-old male mice was $6.89 \pm 0.15$, that was higher $(6.08 \pm 0.14)$ than 3 -wk-old male mice $(\mathrm{P}<0.05)$. But, there was no significant difference between mature and immature mice in FADS1 protein of muscle tissue.

The results suggest that sexual maturity in male increases the level of only FADS1 protein. Thus, we can conclude that sexual maturation in male induces the increase of LA and decrease GLA, DGLA and AA by increasing the level of FASD1 in mouse muscle tissue.

\section{DISCUSSION}

A sexual maturity of animal is known to relate to steroid hormones, progesterone, testosterone, and 17-beta estradiol. Among these steroid hormones, testosterone is most important factor for sexual maturation of male. This study showed higher level of testosterone in mature male sera when compared with immature male mice. Our results are similar as previously reported by Salehzadeh et al. (2011).

Mature male mice with higher testosterone contained higher LA, but lower levels of GLA, DGLA and AA in their M. longissimus compared to immature male mice. This GC experiment suggested that sexual maturation in male mice may inhibit the expression and/or activity of FADS2 and stimulate the RNA and protein expression of ELOVL5 and/or FADS1.

Genes of FADS2, ELOVL5 and FADS1 are involved in n-6 PUFA metabolism (Schmitz and Ecker, 2008; Kong et al., 2009; Guillou et al., 2010). Among these genes, mature male mice showed more expression of ELOVL5 and FADS1 genes in $M$. longissimus in comparison to immature male mice. The real-time PCR experiment supports the previous GC result that sexual maturation in male mice may stimulate the expression of ELOVL5 and/or FADS1.

However, proteins of FADS2, ELOVL5 and FADS1 are directly involved in n-6 PUFA metabolism (Stoffel et al., 2008; Zouboulis et al., 2011). Among these enzymic protein levels, mature male mice showed higher level of FADS1 protein in $M$. longissimus compared with immature male mice. Our Western blotting analysis supports the previous results from $\mathrm{GC}$ and real-time PCR analysis that sexual maturation in male mice may stimulate activity of FADS1. However, this experiment showed that mRNA expression and protein level of ELOVL5 in mature male mice may not coincide. This result suggested that ELOVL5 is different from FADS1 in the expression pattern of gene and protein. Thus, further study is needed to understand the metabolism of ELOVL5 mRNA and protein.

In conclusion, mature male mice showed the increased testosterone level that may affect the n-6 PUFA metabolism in situ environment induced with high testosterone may decrease GLA, DGLA and AA levels in muscle tissue of mature male mice by stimulating the expression of enzyme FADS1 for n-6 PUFA metabolism.

\section{REFERENCES}

Barton, L., Bures, D., Kott, T. and Rehak, D. 2011. Effect of sex and age on bovine muscle and adipose fatty acid composition and stearoyl-CoA desaturase mRNA expression. Meat Sci. 89, 444-450.

Bu, D. P., Wang, J. Q., Dhiman, T. R. and Liu, S. J. 2007. Effectiveness of oils rich in linoleic and linolenic acids to enhance conjugated linoleic acid in milk from dairy cows. J Dairy Sci. 90, 998-1007.

Childs, C. E., Hoile, S. P., Burdge, G. C. and Calder, P. C. 2012. Changes in rat n-3 and n-6 fatty acid composition during pregnancy are associated with progesterone concentrations and hepatic FADS2 expression. Prostaglandins Leukot Essent Fatty Acids. 86, 141-147.

Childs, S., Hennessy, A. A., Sreenan, J. M., Wathes, D. C., Cheng, Z., Stanton, C., Diskin, M. G. and Kenny, D. A. 2008. Effect of level of dietary n-3 polyunsaturated fatty acid supplementation on systemic and tissue fatty acid concentrations and on selected reproductive variables in cattle. Theriogenology. 70, 595-611. 
de Alaniz, M. J. and Marra, C. A. 2003. Steroid hormones and fatty acid desaturases. Prostaglandins Leukot Essent Fatty Acids. 68, 163-170.

Guillou, H., Zadravec, D., Martin, P. G. and Jacobsson, A. 2010. The key roles of elongases and desaturases in mammalian fatty acid metabolism: Insights from transgenic mice. Prog Lipid Res. 49, 186-199.

Kong, X., Ge, H., Chen, L., Liu, Z., Yin, Z., Li, P. and Li, M. 2009. Gamma-linolenic acid modulates the response of multidrug-resistant K562 leukemic cells to anticancer drugs. Toxicol In Vitro. 23, 634-639.

Ogura, T., Takada, H., Okuno, M., Kitade, H., Matsuura, T., Kwon, M., Arita, S., Hamazaki, K., Itomura, M. and Hamazaki, T. 2010. Fatty acid composition of plasma, erythrocytes and adipose: their correlations and effects of age and sex. Lipids. 45, 137-144.

Salehzadeh, F., Rune, A., Osler, M. and Al-Khalili, L. 2011. Testosterone or $17 \beta$-estradiol exposure reveals sex-specific effects on glucose and lipid metabolism in human myotubes. J Endocrinol. 210, 219-229.

Salma, U., Miah, A. G., Maki, T., Nishimura, M. and Tsujii, H. 2007. Effect of dietary Rhodobacter capsulatus on cholesterol concentration and fatty acid composition in broiler meat. Poult
Sci. 86, 1920-1926.

Schmitz, G. and Ecker, J. 2008. The opposing effects of n-3 and n-6 fatty acids. Prog Lipid Res. 47, 147-155.

Senapati, S., Banerjee, S. and Gangopadhyay, D. N. 2008. Evening primrose oil is effective in atopic dermatitis: A randomized placebo-controlled trial. Indian J Dermatol Venereol Leprol. 74, 447-452.

Stoffel, W., Holz, B., Jenke, B., Binczek, E., Gunter, R. H., Kiss, C., Karakesisoglou, I., Thevis, M., Weber, A. A., Arnhold, S. and Addicks, K. 2008. Delta6-desaturase (FADS2) deficiency unveils the role of omega3- and omega6-polyunsaturated fatty acids. EMBO J. 27, 2281-2292.

Weaver, K. L., Ivester, P., Seeds, M., Case, L. D., Arm, J. P. and Chilton, F. H. 2009. Effect of dietary fatty acids on inflammatory gene expression in healthy humans. J Biol Chem. 284, 15400-15407.

Zouboulis, C. C., Angres, S. and Seltmann, H. 2011. Regulation of stearoyl-coenzyme A desaturase and fatty acid delta-6 desaturase-2 expression by linoleic acid and arachidonic acid in human sebocytes leads to enhancement of proinflammatory activity but does not affect lipogenesis. Br J Dermatol. 165, 269-276

(Received Dec. 10, 2012; Revised Feb. 14, 2013; Accepted Apr. 23, 2013) 